\title{
DESKRIPSI PENGETAHUAN IBU HAMIL TENTANG KEHAMILAN EKTOPIK DI POLI KEBIDANAN RSUD ARIFIN ACHMAD PEKANBARU
}

\author{
Juli Widiyanto, Suci Pratiwi \\ Program Studi DIII Keperawatan, Fakultas MIPA dan Kesehatan, Universitas Muhammadiyah Riau \\ Jln. K.H. Ahmad Dahlan No.88 Sukajadi Pekanbaru. \\ e-mail: widiyanto_juli@yahoo.com
}

\begin{abstract}
ABSTRAK
Kehamilan ektopik adalah kehamilan yang terjadi di luar kandungan, di mana sel telur yang telah dibuahi tumbuh dan berimplantasi di tempat yang tidak normal. Kehamilan ektopik merupakan kehamilan yang berbahaya bagi seorang wanita, apabila terlambat mendapat penanganan yang tepat, dapat menyebabkan kondisi yang gawat bagi wanita tersebut. Keadaan gawat ini jika di biarkan dapat menyebabkan kehilangan darah dan berbagai komplikasi yang dapat berakhir dengan kematian. Tujuan Penelitian ini adalah untuk mengetahui gambaran pengetahuan ibu hamil tentang kehamilan ektopik di Poli Kebidanan RSUD Arifin Achmad pekanbaru. Desain penelitian yang digunakan adalah metode deskriptif dengan jumlah sampel 30 responden dengan populasi adalah ibu-ibu hamil di Poli Kebidanan RSUD Arifin Achmad Pekanbaru dengan teknik pengambilan sampel secara accidental sampling. Penelitian ini dilakukan pada tanggal 13-29 Juli 2007 dengan menyebarkan kuesioner yang berisi 20 pertanyaan. Hasil penelitian menunjukkan bahwa gambaran pengetahuan ibu hamil tentang kehamilan ektopik di Poli kebidanan RSUD Arifin Achmad Pekanbaru adalah berpengetahuan kurang sebanyak 21 orang (70\%), cukup sebanyak 8 orang $(26,7 \%)$, dan baik sebanyak 1 orang $(3,3 \%)$. Berdasarkan hasil penelitian tersebut perlu adanya penyebarluasan informasi tentang Kehamilan Ektopik agar pengetahuan ibu hamil meningkat sehingga dapat menurunkan angka kematian ibu.
\end{abstract}

Kata Kunci: Pengetahuan, Kehamilan Ektopik

\section{PENDAHULUAN}

Kesehatan adalah suatu aspek yang paling penting dalam kehidupan manusia. Berbagai upaya dijalankan untuk memelihara kondisi kesehatan atau memulihkan kondisi kesehatan agar kembali seperti sediakala ${ }^{16}$.

Salah satu tantangan berat yang dihadapi Indonesia saat ini adalah masih rendahnya derajat kesehatan kaum ibu, walaupun telah dilakukan berbagai intervensi sejak pencanangan upaya kesejahteraan ibu pada tahun 1988 oleh Presiden Republik Indonesia di Jakarta. Kegagalan dalam penangan kasus kedaruratan obstetri pada umumnya disebabkan oleh kegagalan dalam mengenal resiko kehamilan, keterlambatan rujukan, kurangnya sarana yang memadai untuk perawatan ibu hamil dengan resiko tinggi maupun pengetahuan penderita dalam mengenal kehamilan resiko tinggi (KRT). Pelayanan kedaruratan obstetri di Rumah Sakit rujukan merupakan bagian penting untuk menurunkan Angka Kematian Ibu (AKI) ${ }^{28}$.

Angka kematian ibu di dunia terdapat sekitar 500.000 orang dan kematian perinatal 10.000.000 orang, yang sebagian besar terjadi di negara berkembang. Kenyataan ini mendorong badan dunia WHO dan UNICEF untuk melakukan pertemuan di Alma Ata, Uni Sovyet, 1978 dan mencetuskan landasan filosofi yang ideal sebagai upaya perkembangan pelayanan kesehatan di setiap negara. Landasan tersebut dinyatakan dalam "Primary Health Care" dengan inti mengupayakan pelayanan utama setiap negara sehingga dapat cepat menurunkan angka kematian ibu dan angka kematian perinatal ${ }^{14}$.

Indonesia termasuk negara dengan angka kematian ibu yang cukup tinggi di ASEAN, yaitu sekitar 390/100.000, sedangkan angka kematian perinatal sekitar 540/100.000 persalinan hidup. Jika perkiraan persalinan sekitar 5.000 .000 orang per tahun, Angka Kematian Ibu menjadi 180.000185.000 orang dan Angka Kematian Perinatal menjadi 270.000 orang setiap tahunnya ${ }^{14}$.

Berbagai macam kesulitan dalam proses kehamilan, dialami para wanita yang telah menikah. Meski demikian, tidak menyurutkan keinginan pasangan suami istri untuk memperoleh 
keturunan. Salah satu penyakit dalam proses kehamilan adalah kehamilan ektopik ${ }^{7}$.

Insiden penyakit ini sesungguhnya lebih tinggi dari pada yang dilaporkan. Di Amerika Serikat, kehamilan ektopik terjadi, 1 dalam 64 hingga 1 dalam 241 kehamilan $^{29}$. Negara-negara berkembang khususnya Indonesia, di RSUP Cipto Mangunkusumo pada tahun 1987 terdapat 153 kehamilan ektopik di antara 4.007 persalinan, atau 1 di antara 26 persalinan. Kasus kehamilan ektopik di RSUP dr. M. Djamil padang selama 3 tahun (1992-1994) ditemukan 62 kasus dari 10.612 kehamilan. Angka kekambuhan sebesar 15\% setelah kehamilan ektopik pertama dan meningkat sebanyak 30\% setelah kehamilan ektopik kedua. Sebagian besar wanita yang mengalami kehamilan ektopik berumur antara 20 - 40 tahun dengan umur rata-rata 30 tahun $^{31}$.

Kehamilan ektopik, menurut Abidin dari Rumah Sakit Mitra Keluarga Kelapa Gading, adalah kehamilan yang terjadi di luar kandungan, di mana sel telur yang telah dibuahi tumbuh dan berimplantasi di tempat yang tidak normal ${ }^{2}$.

Kehamilan ektopik tidak bisa dideteksi dari luar. Bila 1-2 minggu si ibu telat menstruasi dan merasa nyeri di perut bagian bawah, nyeri ini terjadi karena kehamilan telah pecah, hingga menimbulkan perdarahan. "Ibu tidak akan tahu karena perdarahan itu terjadi di dalam perut. Hingga, yang ia rasakan hanya sakit yang hebat, lemas, sesak, syok, dan tiba-tiba pingsan". Jika dibiarkan dapat menyebabkan kehilangan darah dan berbagai komplikasi yang dapat berakhir dengan kematian ${ }^{3}$.

Dari data sekunder yang peneliti dapat di RSUD Arifin Achmad pekanbaru berdasarkan data rekam medik, didapat data ibu hamil dengan kehamilan ektopik di Poli Kebidanan RSUD Arifin Achmad Pekanbaru pada tahun 2005 tercatat sebanyak 7 kasus per tahun. Sedan gkan pada tahun 2006 tercatat sebanyak 3 kasus. Pada bulan Maret tahun 2007 tercatat 5 kasus. Sebagian besar wanita yang mengalami kehamilan ektopik berumur antara 25-64 tahun dengan umur rata-rata berkisar antara 25-44 tahun.

Tujuan penelitian ini adalah Untuk mengetahui gambaran pengetahuan ibu hamil tentang kehamilan ektopik di Poli Kebidanan RSUD Arifin Achmad Pekanbaru.

\section{METODOLOGI PENELITIAN}

Jenis penelitian ini adalah deskriptif sederhana dengan desain penelitian cross sectional. Bahan penelitian ini adalah data primer yang diambil dengan penyebaran kuisioner pada responden.

\section{HASIL DAN PEMBAHASAN}

Mayoritas responden di Poli kebidanan RSUD Arifin Achmad Pekanbaru adalah berumur 26-30 tahun yaitu sebanyak 16 orang $(53,3 \%)$. Untuk lebih jelas di tampilkan pada tabel 1.

\section{Tabel 1 Umur Responden di Poli kebidanan RSUD Arifin Achmad Pekanbaru}

\begin{tabular}{|c|c|c|c|}
\hline No & Umur & $\begin{array}{c}\text { Frekuensi } \\
(\mathbf{f})\end{array}$ & $\begin{array}{c}\text { Persentase } \\
(\mathbf{\%})\end{array}$ \\
\hline 1 & $21-25$ & 8 & 26,7 \\
2 & $26-30$ & 16 & 53,3 \\
3 & $31-35$ & 5 & 16,7 \\
4 & $36-40$ & 1 & 3,3 \\
\hline & Jumlah & $\mathbf{3 0}$ & $\mathbf{1 0 0}$ \\
\hline
\end{tabular}

Berdasarkan tabel 1 diatas, dapat dilihat bahwa mayoritas responden di Poli kebidanan RSUD Arifin Achmad Pekanbaru adalah berumur 26-30 tahun yaitu sebanyak 16 orang $(53,3 \%)$.

Penelitian di RS Immanuel menemukan 47 kasus kehamilan ektopik terganggu. Dari 47 kasus KET tersebut, prevalensi tertinggi pada kelompok usia 30-34 tahun yaitu 19 orang (40,43\%). Hasil ini berbeda dengan beberapa penelitian yang menunjukkan KET lebih sering terjadi pada usia yang lebih tua yaitu 35-44 tahun. Mereka mendapatkan wanita usia 35-44 tahun mengalami peningkatan risiko 3-4 kali lipat terhadap KET dibandingkan wanita usia 15-24 tahun, keadaan ini diduga akibat penurunan aktivitas peristaltik saluran tuba ${ }^{7,27}$.

Tabel 2 Pendidikan Responden di Poli Kebidanan RSUD Arifin Achmad Pekanbaru

\begin{tabular}{|c|l|c|c|}
\hline No & Pendidikan & $\begin{array}{c}\text { Frekuensi } \\
\text { (f) }\end{array}$ & Persentase (\%) \\
\hline 1 & SD & 7 & 23,3 \\
\hline
\end{tabular}




\begin{tabular}{|l|l|c|c|}
\hline 2 & SLTP & 14 & 46,7 \\
3 & SMA & 3 & 10 \\
4 & PT & 6 & 20 \\
\hline & Jumlah & $\mathbf{3 0}$ & $\mathbf{1 0 0}$ \\
\hline
\end{tabular}

Berdasarkan tabel 2 diatas, dapat dilihat bahwa mayoritas tingkat pendidikan di Poli Kebidanan RSUD Arifin Achmad Pekanbaru pada kategori tingkat pendidikan rendah (SD, SLTP) yaitu berjumlah 21 orang $(70 \%)$.

Pendidikan formal yang diterima seseorang akan mempengaruhi pengetahuan dan kemampuan seseorang dalam memahami sesuatu ${ }^{17}$.

Tingkat pendidikan mempunyai hubungan yang eksponensial dengan pengetahuan. Semakin tinggi tingkat pendidikan semakin mudah menerima konsep, kreatif dan berkesinambungan. Pendidikan dapat meningkatkan kematangan intelektual seseorang. Kematangan intelektual ini berpengaruh pada wawasan, cara berfikir, baik dalam cara pengambilan keputusan maupun dalam pembuatan kebijakan Rostikawati ${ }^{22}$.

Penelitian di RS Immanuel dijumpai bahwa KET paling sering didapatkan pada paritas pertama yaitu 19 orang $(36,17 \%)$, dengan tingkat pendidikan 10-12 tahun (setara SMU) 70,21\%), keadaan ini terjadi mungkin karena pendidikan rata-rata pasien yang berkunjung ke RS Immanuel adalah setara $\mathrm{SMU}^{7,26}$.

Tabel 3 Pekerjaan Responden di Poli Kebidanan RSUD Arifin Achmad Pekanbaru

\begin{tabular}{|c|l|c|c|}
\hline No & Pekerjaan & Frekuensi (f) & Persentase (\%) \\
\hline 1 & IRT & 23 & 76,7 \\
2 & Swasta & 3 & 10 \\
3 & PNS & 4 & 13,3 \\
\hline & Jumlah & $\mathbf{3 0}$ & $\mathbf{1 0 0}$ \\
\hline
\end{tabular}

Berdasarkan tabel 3 diatas, dapat dilihat bahwa mayoritas pekerjaan responden di Poli Kebidanan RSUD Arifin Achmad Pekanbaru pada kategori Ibu Rumah Tangga (IRT) sebanyak 23 orang $(76,7 \%)$.

Penelitian di RS Immanuel menunjukan bahwa sebagian besar adalah karyawan pabrik sebesar $74,47 \%$, menunjukkan bahwa masyarat yang ber-kunjung ke RS Immanuel sebagian besar merupakan pekerja karyawan pabrik, tetapi masih terlalu dini untuk menarik kesimpulan bahwa pekerjaan karyawan pabrik mempunyai korelasi positif dengan KET, perlu diadakan penelitian lebih lanjut tentang angka kejadian PRP (Penyakit Radang Panggul) di antara karyawan pabrik

penelitiannya yang berjudul “ Hubungan Tingkat Pengetahuan Ibu tentang Stimulus dengan Perkembangan Motorik Kasar Anak Usia 3-5 Tahun di Serdang Bedagai”, yang mengatakan bahwa salah satu faktor yang mempengaruhi pengetahuan adalah pekerjaan ${ }^{32}$.

Tabel 4 Informasi yang Diperoleh Responden Tentang Kehamilan Ektopik

\begin{tabular}{|c|l|c|c|}
\hline No & Kategori & Frekuensi (f) & Persentase (\%) \\
\hline 1 & Pernah & 9 & 30 \\
2 & Tidak pernah & 21 & 70 \\
\hline & Jumlah & $\mathbf{3 0}$ & $\mathbf{1 0 0}$ \\
\hline
\end{tabular}

Berdasarkan tabel 4 diatas, dapat dilihat bahwa mayoritas informasi yang diperoleh responden di Poli Kebidanan RSUD Arifin Achmad Pekanbaru pada kategori tidak pernah mendapatkan informasi sebanyak 21 orang (70\%).

Pengetahuan kurang sangat dipengaruhi oleh kuragnya keterpaparan terhadap informasi dan seseorang yang pernah mendapatkan informasi atau penyuluhan maka pengetahuannya akan bertambah ${ }^{20}$.

Meningkatkan pengetahuan kesehatan masyarakat terutama pada ibu hamil, dimana pendidikan kesehatan ibu-ibu hamil dapat dilakukan pada waktu pengawasan hamil di Puskesmas atau Pondok Bersalin Desa dan Bidan Praktek Swasta, saat penyelenggaraan Posyandu, dan saat diadakannya pertemuan atau kegiatankegiatan di lingkungannya dan saat melakukan kunjungan rumah ${ }^{14}$.

Informasi adalah salah satu organ pembentuk pengetahuan dan memegang peranan besar dalam membangun pengetahuan. Semakin banyak seseorang memperoleh informasi, maka semakin baik pula pengetahuannya, sebaliknya semakin kurang informasi yang diperoleh, maka semakin kurang pengetahuannya ${ }^{24}$.

Media massa adalah suatu jenis komunikasi yang ditunjukkan kepada sejumlah masyarakat 
melalui media cetak dan media elektronik sehingga peran informasi yang sama dapat diterima secara serentak ${ }^{22}$.

Media massa merupakan sumber utama dari pencitraan sosial dan wadah bagi identitas. Dengan demikian, media massa menempati posisi penting dalam masyarakat dan memiliki potensi untuk dikembangkan untuk kepentingan tertentu ${ }^{21}$.

Tabel 5 Pengetahuan Responden Tentang Kehamilan Ektopik

\begin{tabular}{|c|l|c|c|}
\hline No & Kategori & Frekuensi (f) & Persentase (\%) \\
\hline 1 & Baik & 1 & 3,3 \\
2 & Cukup & 8 & 26,7 \\
3 & Kurang & 21 & 70 \\
\hline \multicolumn{2}{|c|}{ Jumlah } & $\mathbf{3 0}$ & $\mathbf{1 0 0}$ \\
\hline
\end{tabular}

Berdasarkan tabel 5 di atas, dapat dilihat bahwa mayoritas pengetahuan ibu hamil tentang Kehamilan Ektopik di Poli Kebidanan RSUD Arifin Achmad Pekanbaru adalah berada dalam kategori kurang yaitu sebanyak 21 orang orang (70\%).

Penelitiannya tentang kehamilan ektopik pada ibu hamil di Polindes Kemuning Desa Tasik Madu Kecamatan Palang Tuban terhadap 20 responden yang mengatakan bahwa pengetahuan ibu hamil tentang kehamilan ektopik termasuk dalam kategori kurang yaitu sebanyak 12 orang $(60 \%)^{30}$.

Hasil analisa data tabulasi silang, peneliti berasumsi bahwa pengetahuan ibu hamil tentang kehamilan ektopik di Poli Kebidanan RSUD Arifin Achmad Pekanbaru dalam kategori kurang, dapat dipengaruhi oleh beberapa faktor antara lain faktor pendidikan, dimana hasil penelitian menunjukkan bahwa mayoritas responden adalah berpendidikan rendah (SD, SLTP) yaitu berjumlah 19 orang $(63,3 \%)$.

\section{DAFTAR PUSTAKA}

http://id.wikipedia.org

Anonim. (2006). Gejala awal kehamilan. Diperoleh pada tanggal 13 September 2007. http://portal.cbn.net.id
(2006). Kehamilan ektopik. Diperoleh pada tanggal 10 September 2007. http://cpddokter.com/home/index

Cunningham FG, Gant NF, Loveno KJ, Gilstrap LC, Hauth JC, Wenstom KD, penyunting. Williams Obstetrics. Edisi ke-21. 2003; 883-904.

Luhan. (2000). Informasi sebagai sumber informasi. Diperoleh pada tanggal 27 Juli 2007. http://kompas.com

---------. (2007). Pengantar kuliah obstetri. Jakarta: EGC

Netty, S. (2006). Kehamilan Ektopik. Diperoleh pada tanggal 26 Maret 2007. http://sariwiryanetty.blogspot.com/2009/07/ abortus.html

Nuryati, I. (2006). Kehamilan Ektopik. Diperoleh pada tanggal 09 Juli 2007. http://nuryati.wordpress.com/2009/02/13/ke hamilan-ektopik-terganggu

Permata. (2002). Hubungan antara pendidikan dengan informasi. Di peroleh pada tanggal 29

Juli

2007. http://wordpress.com/2002/02/15/html

Quail. (2000). Media Literalisasi kritis. Di peroleh pada tanggal 27 Juli 2007. http://www.kompas.com

Sakjono. (2000). Psikologi Perkembangan. Diperoleh tanggal 27 Juli 2007. http://id.wikipedia.org

Sepilian V, Wood E. Ectopic pregnancy. Fertil Steril, 2000; 57: 456-8. Dari: http://www.emedicine.com/. Di akses 12 Maret 2007.

Simon. (1999). Hubungan pengetahuan dengan umur. Diperoleh pada tanggal 29 Juli 2007. http://www.wordpress.com

Siska, V. (2006). Kehamilan Ektopik. Diperoleh pada tanggal 30 Oktober 2007. http://violitasiskamutiara.blogspot.com/200 9/01/kehamilan-ektopik.html

Syamsul. (2003). Kehamilan Ektopik. Diperoleh pada tanggal 10 September 2007. http://library.usu.ac.id/download/fk/obstetri -syamsul.pdf

Teguh, M. (2006). Kehamilan Ektopik. Diperoleh pada tanggal 09 Juli 2007. 
http://www.teguh-skep-ns.co.cc/2010-03-

01-archive.html

Wahyuni. (2006). KTI kehamilan ektopik.
Diperoleh pada tanggal 27 Juli 2007. http://wahyuni.blogspot.com/2009/02/html.

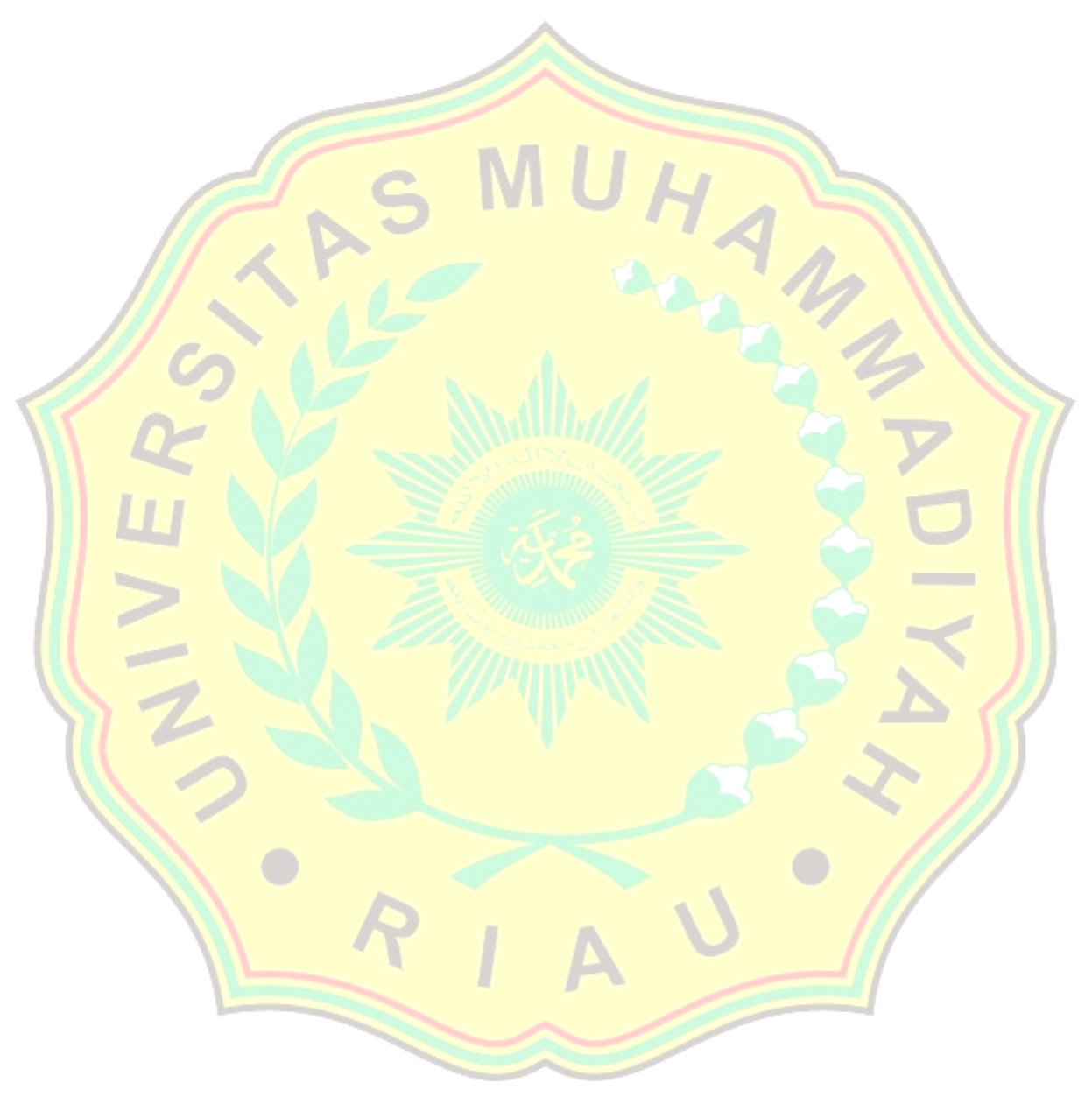

